\title{
Stroke Interventions by Non-Neurointerventionists: Learning from Indian Epic Mahabharata
}

\author{
Vikas Bhatia1® Ajay Kumar $^{1} \quad$ Sucharita Ray ${ }^{2}$ \\ ${ }^{1}$ Department of Radio-Diagnosis, PGIMER Chandigarh, Chandigarh, \\ India \\ ${ }^{2}$ Department of Neurology, PGIMER Chandigarh, Chandigarh, India \\ J Clin Interv Radiol ISVIR 2022;6:217-219.
}

\author{
Address for correspondence Vikas Bhatia, DM, Department of Radio- \\ Diagnosis, Section of Neuroimaging and Interventional \\ Neuroradiology, PGIMER Chandigarh, Chandigarh, India \\ (e-mail: drvikasbhatia@gmail.com).
}

Mechanical thrombectomy (MT) has become the gold-standard treatment for large vessel occlusion. Recently, there has been a growing interest in the cardiology community to perform MT in acute ischemic stroke (AIS) patients.

The good intentions to treat such patients when a neurointerventionist is not available reminds us of the story of the great warrior Abhimanyu from the Indian epic Mahabharata. ${ }^{1}$ The story of Abhimanyu (-Fig. 1), is a perfect example of bravery yet shows the hazards of possessing incomplete knowledge. Abhimanyu had learned breaking into battle formation-the "chakravyuh" (chakra-round, vyuh-formation), while he was still in his mother's womb. One day when still in the womb, his mother fell asleep and he could only partly learn the process. Later, on one fateful day during the Mahabharata war, when Arjuna was away there was no choice but to use young Abhimanyu to penetrate the "chakravyuh." Although he fought with bravery, ultimately his partial knowledge got the better of him and, unable to extricate himself out of the "chakravyuh," he finally perished on the battlefield.

For the sake of our discussion, let us view now Abhimanyu as a non-neurointerventionist who has to take up the chakravyuh (AIS) when the experienced warrior Arjuna (neurointerventionists) is not present.

Life is a chakravyuha-a complicated situation like acute stroke can present any time:

Mahabharata reminds us that a tough situation can appear at any time in our life. The incidence of stroke is indeed very high with an ever-increasing demand for an interventionist to perform acute stroke interventions. It requires rapid training of suitable manpower which includes interventionists, health care workers, trained stroke nurses, bet- ter teleradiology and communication systems, a dedicated stroke protocol, and community-based approaches. ${ }^{2}$

The thought of acquiring more only brings destruction (any new intervention should be based on need not desire):

The desire of acquiring more and dissatisfaction was the core of Mahabharata. Whenever a Level I guideline is given, there are tremendous efforts by the researchers working in that field. ${ }^{3}$ The moral is that while it is true that more hands are needed to fill the gaping shortage of neurointerventionists, however, the desire to enter a field evolved and firmly entrenched by other specialties should purely be based on goodwill to provide benefit to the patient community and not competitive.

\section{Always Gain Complete Knowledge of Anything}

Abhimanyu could never strive toward learning a way to demolish the formation and find a way out of it. There is a learning curve in any intervention which requires complete knowledge of anatomy, pathology, hardware, complications, and many more. We should not be just glad to perform a straightforward case with a good outcome but be also afraid of the complicated situations which require greater experience.

\section{Incomplete Knowledge is too Dangerous}

Abhimanyu is the perfect example to show that although he was valiant, he lacked complete knowledge. There is no doubt on the clinical acumen or intervention capabilities of our non-neurointervention colleagues, however, there are key differences in the vessel anatomy, hardware, and pathophysiology of disease when considering intracranial versus article published online January 11, 2022
DOI https://doi.org/ 10.1055/s-0041-1740573. ISSN 2457-0214. (c) 2022. Indian Society of Vascular and Interventional Radiology. All rights reserved.

This is an open access article published by Thieme under the terms of the Creative Commons Attribution-NonDerivative-NonCommercial-License, permitting copying and reproduction so long as the original work is given appropriate credit. Contents may not be used for commercial purposes, or adapted, remixed, transformed or built upon. (https://creativecommons.org/ licenses/by-nc-nd/4.0/)

Thieme Medical and Scientific Publishers Pvt. Ltd., A-12, 2nd Floor, Sector 2, Noida-201301 UP, India 


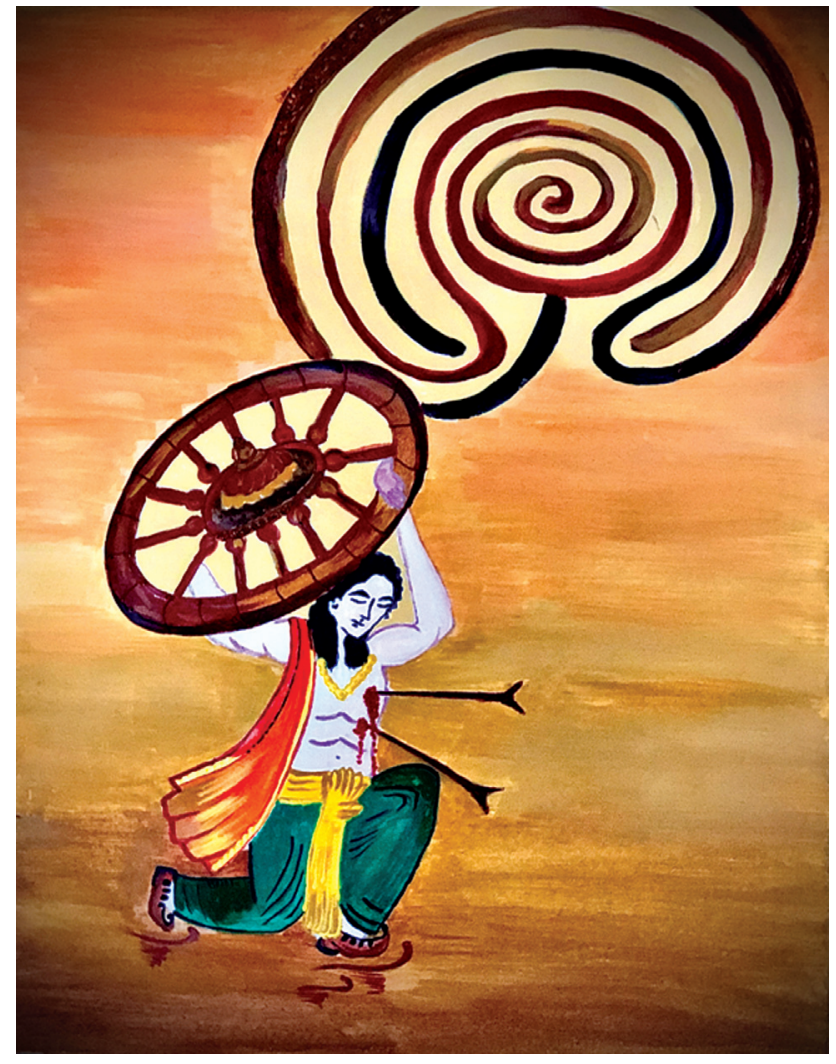

Fig. 1 Injured Abhimanyu fighting on the battlefield.

extracranial, for example, coronary interventions. MT is not only composed of intervention part but also requires deep knowledge of advanced imaging. ${ }^{3}$

\section{Don't Lose Your Strength during Tough Time}

Abhimanyu showed exemplary strength and bravery, even though he was attacked from all fronts. Stroke interventions are challenging and require utmost calm and composed nerves while interpreting a variety of data and patient parameters. It is important to always learn from the masters in a particular field to attain such calm in tough situations and follow the guidelines set by societies.

\section{Strive to Gain Excellence in Knowledge}

Abhimanyu's passion for both education and workability was commendable as he started gaining knowledge from the womb of his mother. This is required in real-world situations like stroke too. However, it is also imperative to get proper training before performing intervention in unfamiliar territory. The knowledge of imaging criteria, time windows, and cohort of patients that can be imaged are rapidly evolving. ${ }^{3}$

- Table 1 shows the studies demonstrating the MT in AIS performed by interventional cardiologists. ${ }^{4-7}$ These results looks encouraging; however, it is important to mention that they are mostly single-center nonrandomized studies as compared with multiple randomized trials where neurointerventionists have performed stroke interventions. ${ }^{3}$

Potential solutions for greater availability of MT and to reduce the turf of war between the neuroscience trained and untrained physicians performing MT are:

- "Hub-and-spoke model" for transfer of stroke patients between hospitals.

- Training more neurointerventionists.

- Training of the noninvasive neurologists:

- Formation of a multidisciplinary group for stroke intervention, with members from neurology, cardiology, vascular medicine, radiology, and neurosurgery disciplines.

- Formation of an apex stroke intervention regulatory authority at national level.

To conclude, we must all unite for greater benefit to mankind and society. We should remember this important quote by Jimmy carter when we do so:

"We must adjust to changing times and still hold to unchanging principles"

Table 1 Studies where mechanical thrombectomy was performed by cardiologists

\begin{tabular}{|c|c|c|c|c|c|c|}
\hline Study & Type of study & $\begin{array}{l}\text { Number of } \\
\text { patients }\end{array}$ & $\begin{array}{l}\text { Mortality at } \\
1-3 \text { mo (\%) }\end{array}$ & $\begin{array}{l}\mathrm{mRS} \text { at } \\
3 \mathrm{mo}(\%)\end{array}$ & $\begin{array}{l}\mathrm{TICl} 2 \mathrm{~b} / 3 \\
\text { recanalization } \\
(\%)\end{array}$ & Interventionist \\
\hline Htyte et al ${ }^{4}$ & $\begin{array}{l}\text { Single center } \\
\text { nonrandomized }\end{array}$ & 54 & 16 & 45 & 78 & $\begin{array}{l}\text { Interventional cardiologists } \\
(47 \%) \text { patients } \\
\text { neurointerventionalists (53\%) }\end{array}$ \\
\hline Widimsky et al ${ }^{5}$ & $\begin{array}{l}\text { Three European } \\
\text { centers }\end{array}$ & 84 & 11 & 36 & 72 & $\begin{array}{l}\text { Interventional cardiologists } \\
\text { in partnership with } \\
\text { noninvasive neurologists }\end{array}$ \\
\hline Guidera et $\mathrm{al}^{6}$ & Single center & 40 & 15 & 55 & 80 & $\begin{array}{l}\text { Interventional cardiologists } \\
\text { with carotid stenting } \\
\text { experience working closely } \\
\text { with neurologists }\end{array}$ \\
\hline Hornung et $\mathrm{al}^{7}$ & Single center & 70 & 18 & 61 & 93 & $\begin{array}{l}\text { Interventional cardiologists } \\
\text { with carotid stenting } \\
\text { experience working closely } \\
\text { with neurologists }\end{array}$ \\
\hline
\end{tabular}

Abbreviations: mRS, modified Rankin scale; $\mathrm{TICI}$, Thrombolysis in Cerebral Infarction. 
We state that this article is not submitted to any other journal and is our original work.

IEC - approved.

Funding

None.

\section{Conflict of Interest}

None declared.

Acknowledgment

We would like to thank Ms. Neha Chaudhary, Nursing officer PGIMER Chandigarh, for the Abhimanyu image sketch.

\section{References}

1 Aggarwal P. 11 Lessons from Mahabharat Abhimanyu, Beauty of soul. 2020. Accessed July 20, 2020 at: https://beautyofsoul.com/blog/mahabharat-abhimanyu-lessons-story/
2 Clarke DJ, Forster A. Improving post-stroke recovery: the role of the multidisciplinary health care team. J Multidiscip Healthc 2015;8:433-442

3 Goyal M, Menon BK, van Zwam WH, et al; HERMES collaborators. Endovascular thrombectomy after large-vessel ischaemic stroke: a meta-analysis of individual patient data from five randomised trials. Lancet 2016;387(10029):1723-1731

4 Htyte N, Parto P, Ragbir S, Jaffe L, White CJ. Predictors of outcomes following catheter-based therapy for acute stroke. Catheter Cardiovasc Interv 2015;85(06):1043-1050

5 Widimsky P, Asil T, Abelson M, et al. Direct catheter-based thrombectomy for acute ischemic stroke: outcomes of consecutive patients treated in interventional cardiology centers in close cooperation with neurologists. J Am Coll Cardiol 2015;66(04): 487-488

6 Guidera S, Boland D, McGarvey J, et al. TCT-210 3 year experience with cath lab based acute stroke rescue program in a community hospital. J Am Coll Cardiol 2018;72(Suppl 13):B88

7 Hornung M, Bertog SC, Grunwald I, et al. Acute stroke interventions performed by cardiologists: initial experience in a single center. JACC Cardiovasc Interv 2019;12(17):1703-1710 